\title{
A rare case: Falsely positive ECG for ASMI in patient with ASD admitted with acute coronary syndrome
}

\author{
Abdullah Icli *, Mehmet Kayrak \\ Department of Cardiology, Necmettin Erbakan University, Meram School of Medicine, Konya, Turkey
}

\section{A R T I C L E I N F O}

\section{Article history:}

Received 3 May 2016

Received in revised form 29 May 2016

Accepted 31 May 2016

Available online 4 June 2016

\section{Keywords:}

Myocardial infarction

Atrial septal defect

Electrocardiogram

\begin{abstract}
A B S T R A C T
Electrocardiogram (ECG) is widely used in the diagnosis of myocardial infarction (MI). It mostly gives important hints to detect the infarct-related artery (IRA). The changes in the morphology and in the position of the heart cause changes in ECG as well. Though ECG is used for the diagnosis of MI, it is not sufficient on its own in detecting the location of the underlying lesion. The pathologies changing the morphology of the heart, such as the atrial septal defect (ASD), increase the margin of error of ECG. We report a rare case; falsely positive ECG for anteroseptal MI in patient with ASD admitted with acute coronary syndrome. Coronary angiography revealed right coronary artery (RCA) lesion in the patient with acute MI who was found to have ST elevation in both precordial and inferior derivations. As a potential cause of mismatch between IRA and infarct location at ECG, echocardiography showed right ventricle dilatation related with cribriform ASD. It was percutaneously closed at 30 days after MI. Therefore, when observed a mismatch between IRA and infarct location at ECG, a detailed examination should be performed to determine potential causes of the mismatch.

(C) 2016 The Society of Cardiovascular Academy. Production and hosting by Elsevier B.V. All rights reserved. This is an open access article under the CC BY-NC-ND license (http://creativecommons.org/licenses/by-nc-nd/4.0/).
\end{abstract}

\section{Introduction}

ECG is widely used in the diagnosis of MI. It mostly gives important hints to detect the IRA. ${ }^{1}$ ST elevation at anteroseptal derivation of ECG (precordial V1-4 leads) is frequently related with mid lesions of left anterior descending artery (LAD). Rarely, mid LAD occlusions cause to ST elevation at inferior derivation in addition to anteroseptal changes when LAD surrounded the apex. ${ }^{2}$ The changes in the morphology and in the position of the heart cause changes in ECG as well. A coronary angiography revealed RCA lesion in our patient with acute MI who was found to have ST elevation in both precordial and inferior derivations. Subsequent echocardiography showed us the ASD enlarging the right ventricle which we closed 30 days after the MI. In current literature, it has been reported that non-dominant RCA occlusions may present ST elevation at V1-3 leads. ${ }^{3}$ Also, ST-segment elevation in leads V1-4 has been reported during isolated right ventricle MI. ${ }^{4}$

We present an anteroseptal MI pattern related with RCA occlusion in patient with ASD as rare cause of mismatch between ECG and IRA.

\footnotetext{
* Corresponding author at: Department of Cardiology, Necmettin Erbakan University, Meram School of Medicine, Konya, Turkey, 42080. Tel.: +90 54245768 03; fax: +90 3322236065 .

E-mail addresses: abdullahicli@yahoo.com, aicli@konya.edu.tr (A. Icli).

Peer review under responsibility of The Society of Cardiovascular Academy.
}

\section{Case}

The 56-year-old male patient was admitted to the Emergency Department at the 2 nd hour of the clamping chest pain. The first ECG revealed a $1 \mathrm{~mm}$ ST elevation in V1-4 and D3-AVF (Fig. 1). When the coronary angiography showed a recanalization and thrombosis in severe RCA lesion, stent implantation was performed. The postoperative ECG revealed ST resolution (Fig. 2). Fig. 3 shows the coronary angiography procedure performed. A control angiography was performed upon the presence of chest pain and similar changes in the ECG in the follow-up period. It was seen that the RCA was blocked. Medical intervention was made and TIMI-3 flow was enabled.

The echocardiography revealed $50 \%$ election fraction, enlarged right ventricle, $2^{\circ}$ tricuspid insufficiency, $35 \mathrm{mmHg}$ pulmonary artery pressure estimated by the tricuspid insufficiency jet, and negative and positive contrast transmission in $\mathrm{Qp} / \mathrm{Qs}=1.7$ subcostal examination (Fig. 4). Transesophageal echocardiography revealed many cribriform type ASD of which the largest was $6 \mathrm{~mm}$. The whole cribriform region was detected to be $20 \mathrm{~mm}$ wide. The patient with enlarged right ventricles and a ratio of Qp/Qs $=1.7$ underwent the percutaneous ASD closure procedure 30 days after the MI (Fig. 5).

\section{Discussion}

Elevation in both inferior and anterior derivations is not common in the patients admitted with acute MI. This may be caused by the LAD lesions surrounding the apex in these patients. ${ }^{2}$ In their study on 885 


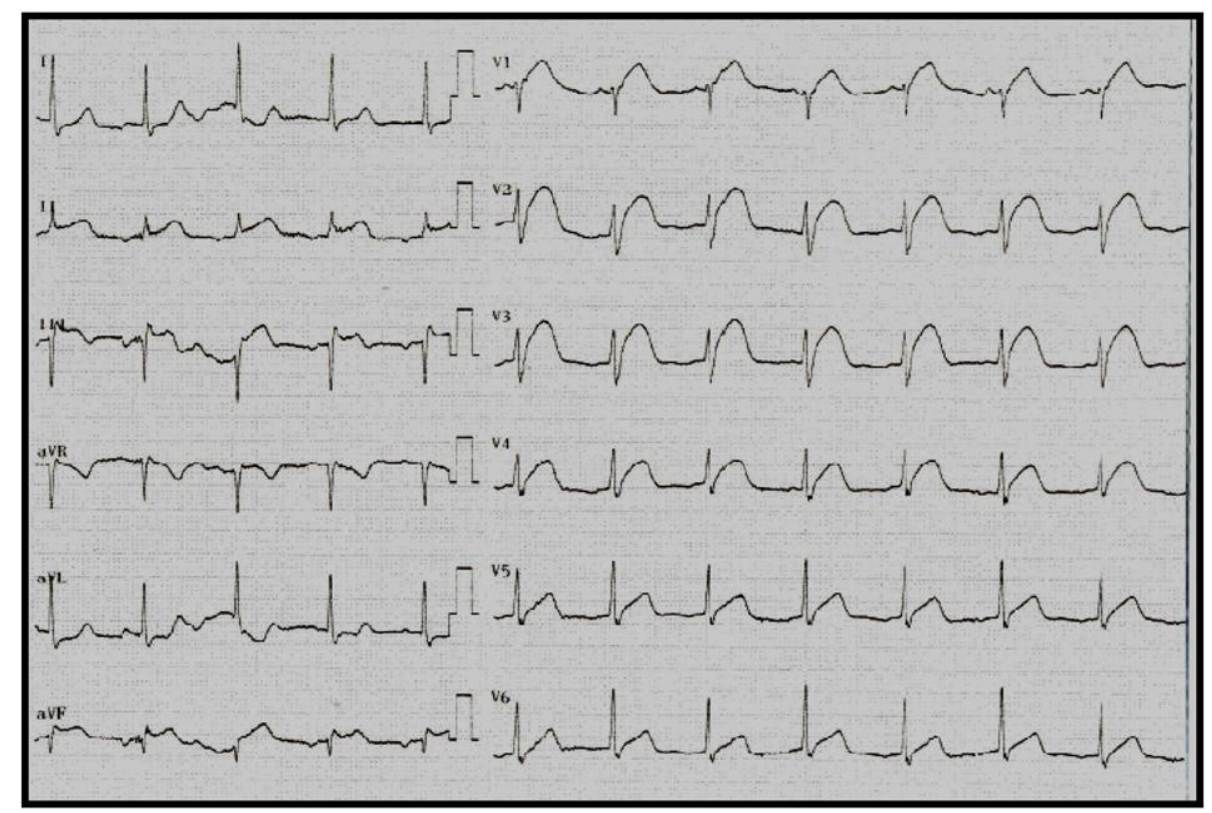

Fig. 1. Electrocardiogram during chest pain. ST in V1-4 and D2-3 aVF.

patients with ST elevation, Taglieri et al. detected ST elevation in anterior and inferior derivations in 8 (1\%) patients. ${ }^{5}$ In the study by Yip et al., simultaneously ST elevations in precordial and inferior derivations were found in 37 (4\%) of 924 acute MI patients. LAD lesions surrounding the apex were detected in $8(21 \%)$ of these 37 patients. This was associated with the high number of coronary artery lesions in other patients. ${ }^{6}$ On the other hands, it has been reported that non-dominant RCA occlusions may present ST elevation at V1-3 leads. ${ }^{3}$ Also, Kinch and Ryan reported to ST-segment elevation in leads V1-4 during isolated right ventricle MI. ${ }^{4}$
Patients suffering from MI with ASD have been reported in the literature. ${ }^{7}$ Right-to-left shunt may be seen in the patients with ASD following right ventricular infarction. ${ }^{8-10}$ We detected RCA lesion in the patient with ST elevation in anterior and inferior derivations. Anatomical properties of RCA are compatible with right dominance at the coronary supply. The subsequent echocardiography revealed that the right ventricle was enlarged secondarily to cribriform ASD. We postulated that the right ventricle enlarged secondarily to ASD in the patient caused rotation of the heart which, in turn, led to ST elevation in precordial derivations.

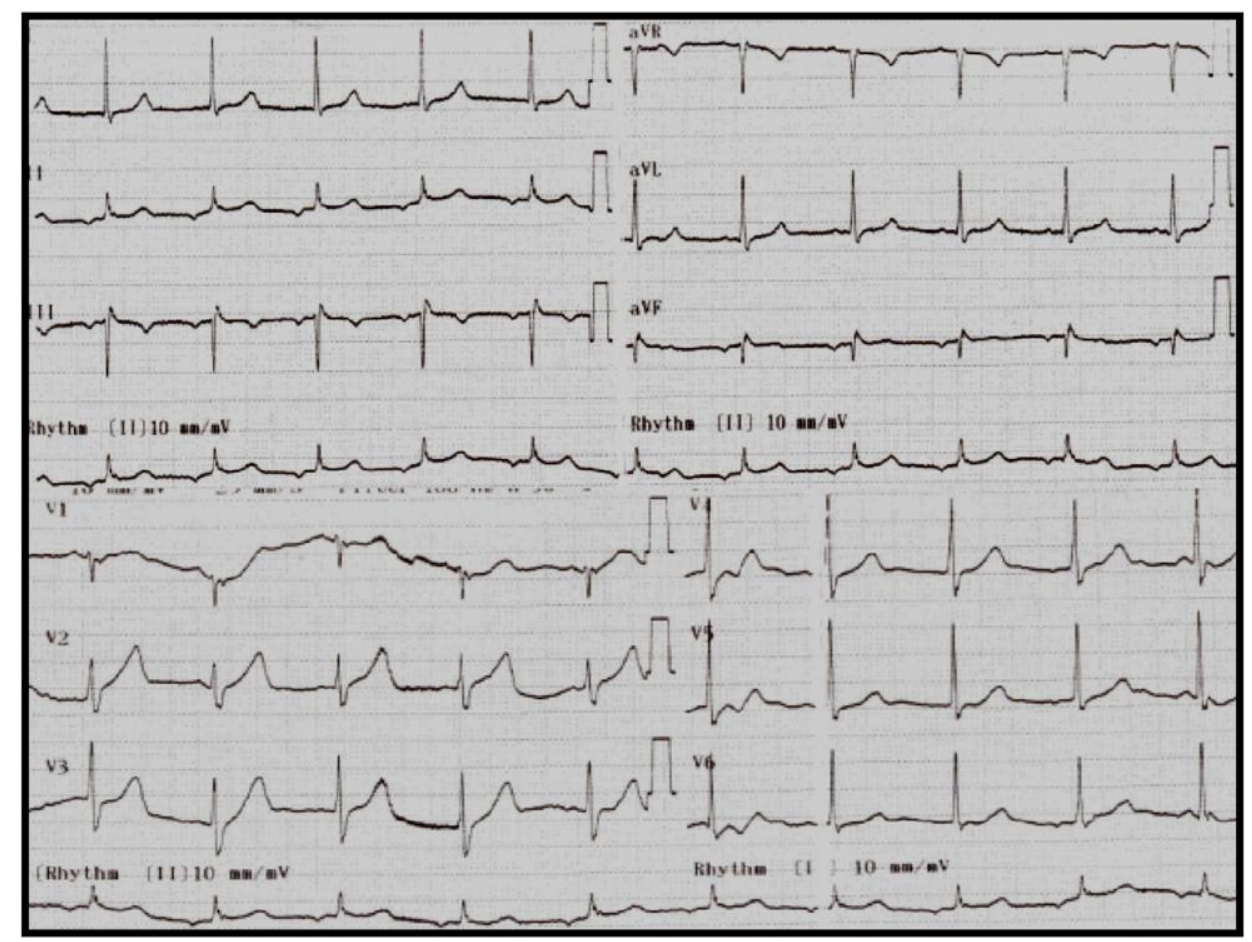

Fig. 2. Electrocardiogram following the stent implantation in the patient's right coronary lesion. ST resolution can be seen in inferior and anterior derivations. 


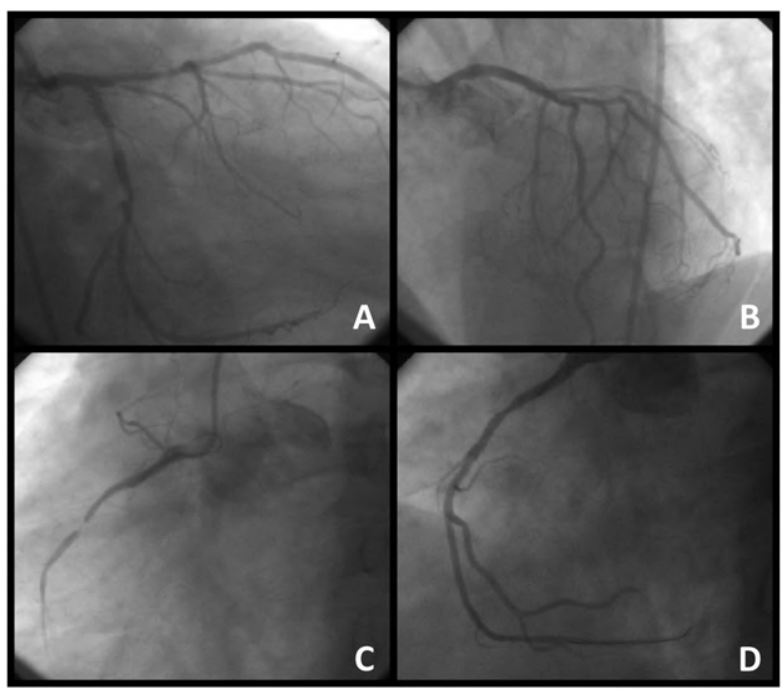

Fig. 3. Coronary angiographic images: A: Right anterior oblique-caudal angle; B: Right anterior oblique-cranial angle; C: Underlying lesion in RCA; D: Angiographic image after stent implantation in RCA.

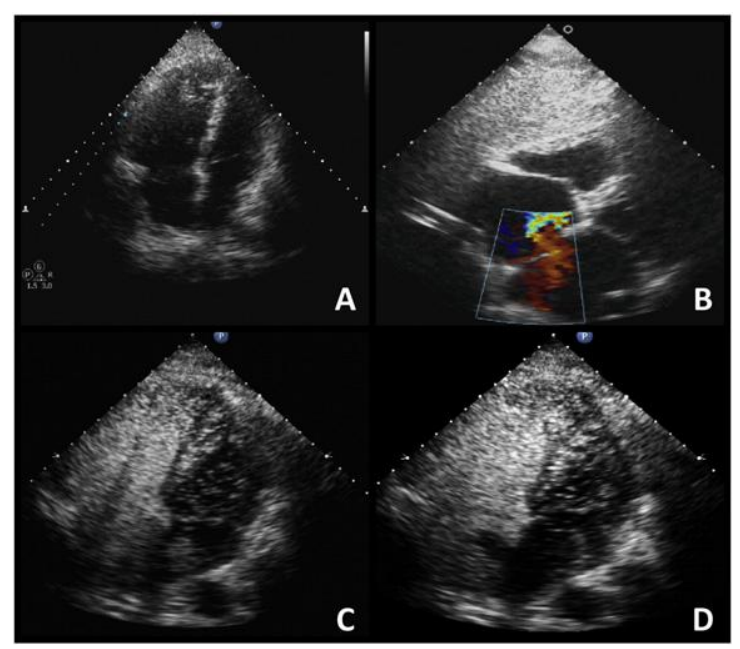

Fig. 4. Echocardiographic images: A: Enlarged right ventricles in parasternal long axis image; B: Color transition with the use of interatrial Doppler in the subcostal examination; C: Positive contrast transition in the contrast examination; D: Negative contrast transition in the contrast examination.

\section{Conclusion}

Though ECG is used for the diagnosis of MI and IRA, it is not sufficient on its own in detecting IRA and the location of the underlying lesion. The pathologies changing the morphology of the heart, such as ASD, increase the margin of error of ECG. Hence, a detailed examination should be performed to determine of potential cause of mismatch between IRA and infarct location at ECG.

\section{References}

1. Thygesen K, Alpert JS, Jaffe AS, Simoons ML, Chaitman BR, White HD. Third universal definition of myocardial infarction. ESC/ACCF/AHA/WHF task force for the universal definition of myocardial infarction. Eur Heart J 2012;33:2551-2567.

2. Akpinar I, Arat N, Ozbülbül NI. A case of simultaneous anterior, inferior, and right ventricular ST-segment elevation myocardial infarction due to occlusion of the wrapped left anterior descending coronary artery. Turk Kardiyol Dern Ars 2008;36: 335-337.

3. Franco JJ, Brown M, Bashir R, O'Murchu B. Acute anterior ST-elevation myocardial infarction and electrical storm secondary to Nondominant right coronary artery occlusion. Tex Heart Inst J 2014;41:335-337.

4. Kinch JW, Ryan TJ. Right ventricular infarction. N Engl J Med 1994;330:1211-1217.

5. Taglieri N, Saia F, Alessi L, et al. Diagnostic performance of standard electrocardiogram for prediction of infarct related artery and site of coronary occlusion in unselected STEMI patients undergoing primary percutaneous coronary intervention. Eur Heart J Acute Cardiovasc Care 2014;3:326-339.

6. Yip HK, Chen MC, Wu CJ, et al. Acute myocardial infarction with simultaneous ST-segment elevation in the precordial and inferior leads: evaluation of anatomic lesions and clinical implications. Chest 2003;123:1170-1180.

7. Pernencar S, Costa M, Mota P, Leitão-Marques A. Acute myocardial infarction in a young adult with an atrial septal defect. Intensive Care Med 2001;27:323-324.

8. Sánchez-Ramos J, Colmenero M, Romero JA, Fernández MA, Moreno T, Azpitarte J. Right-to-left interatrial shunt secondary to right ventricular myocardial infarction: a novel therapeutic approach. J Rev Port Cardiol 2007;26:1079-1081.

9. Fessler MB, Lepore JJ, Thompson BT, Semigran MJ. Right-to-left shunting through a patent foramen ovale in right ventricular infarction: improvement of hypoxemiaand hemodynamics with inhaled nitric oxide. J Clin Anesth 2003;15:371-374.

10. Silver MT, Lieberman EH, Thibault GE. Refractory hypoxemia in inferior myocardial infarction from right-to-left shunting through a patent foramen ovale: a case report and review of the literatüre. Clin Cardiol 1994;17:627-630.

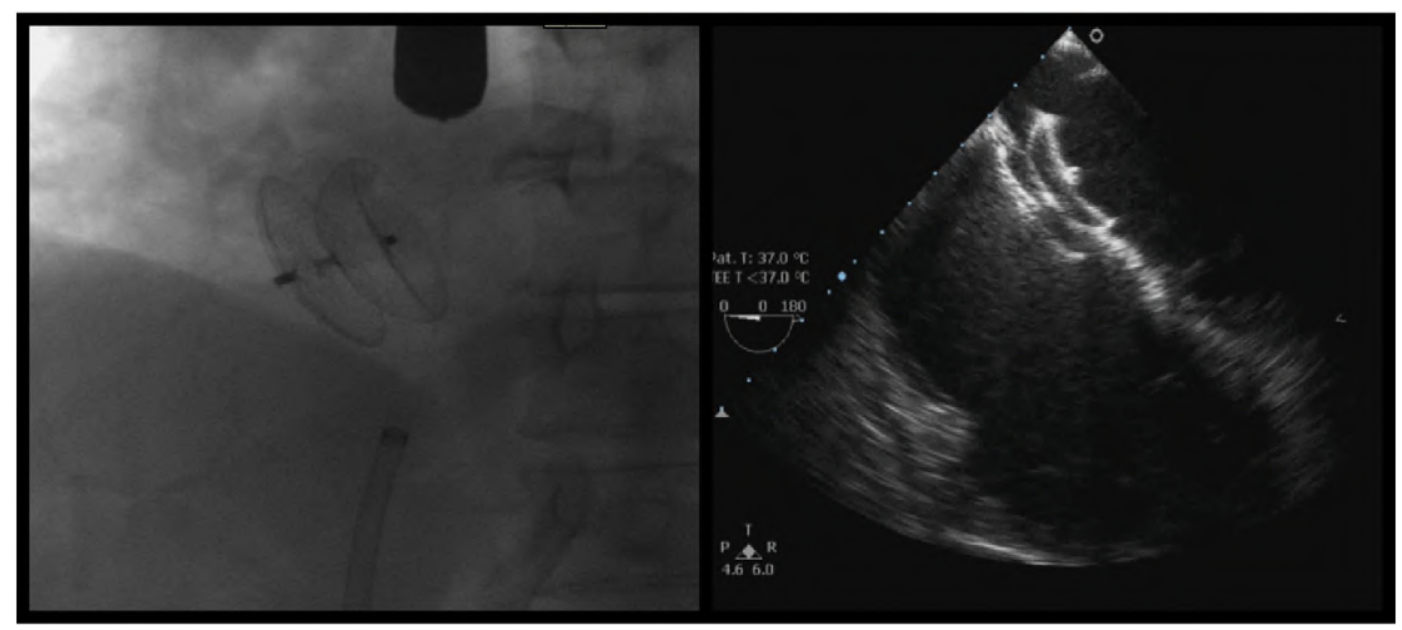

Fig. 5. Amplatz catheter was placed in the interatrial septal defect. Angiographic and TEE images are seen. 